\title{
Stimulation of Executive Functions as Part of the Language Intervention Process in Children with Autism Spectrum Disorder
}

\author{
Ingrid Ya I. Sun ${ }^{a}$ Cristina Andrade Varanda ${ }^{a}$ b Fernanda Dreux Fernandes ${ }^{a}$ \\ a Department of Physical Therapy, Speech-Language Pathology and Audiology, and Occupational Therapy, School \\ of Medicine, Universidade de São Paulo (FMUSP), São Paulo, Brazil; ' ${ }^{b}$ Universidade Paulista (UNIP), Santos, Brazil
}

\section{Keywords}

Autism · Language $\cdot$ Pragmatics $\cdot$ Cognition · Executive function

\begin{abstract}
Aims: Identifying effective methods for stimulating language and communication of children with autism spectrum disorder (ASD) is fundamental to the effective use of available resources to support these children. This pilot study was designed to explore the potential benefits of a program of stimulation of executive functions (SEF) on the functional aspects of language and communication through the assessment of the functional communicative profile and social-cognitive performance. Methods: Twenty children, aged 5-12 years, with a diagnosis of ASD participated in the study. Two stimulation programs were offered over a 10- to 12-week period as part of the regular services offered to these children through a University's speech and language therapy outpatient clinic in São Paulo, Brazil. Children either received SEF intervention in their home implemented by their parent/s, with close monitoring by the speech-language pathologist (SLP) (group 1), or they received SEF by the SLP during regular speech-language therapy individual sessions (group 2). Results: The findings suggested that
\end{abstract}

\section{KARGER}

(c) 2017 S. Karger AG, Basel

E-Mail karger@karger.com

www.karger.com/fpl there were differences between the children's pre- and posttest performance. Significantly different performances were observed in the areas of occupation of communication space, proportion of communicative interactivity, and social-cognitive performance. Conclusion: The inclusion of activities to stimulate executive function abilities in language intervention for children with ASD warrants further investigation.

(c) 2017 S. Karger AG, Basel

\section{Introduction}

Throughout the years, despite variations in diagnostic criteria and classification, descriptions of autism spectrum disorder (ASD) include impairments in language and communication [1]. Identifying effective methods for stimulating language and communication in children with ASD is fundamental to the adequate use of resources, such as specialized intervention and education, especially in regions of the world where this population is underserved or where geographic distances impede access to appropriate intervention.

The close association between language development and executive functions (EFs) has been studied for de- 
cades regarding specific aspects, such as meta-representation and syntactic awareness in children with ASD and Asperger syndrome [2-4]. However, it is still not clear if there is a causal relationship between them. A recent literature review [5] indicates that there is evidence of a moderate association between EFs and academic achievements but little evidence of causality. The authors also report that there is evidence that EFs can be improved by intervention.

EFs are understood as the ability to manage the mental processes that organize, control, program, and monitor perceptual and motor information already stored in memory. Numerous studies have focused on understanding the association between EFs and ASD [6-14]. These abilities enable the individual to define a goal, plan necessary actions, execute and monitor goals, adjusting actions as necessary, and assess the outcome of the actions [15, 16]. Stemmer and Whitaker [17] suggest that EFs include the abilities of self-control, working memory, cognitive flexibility, and central coherence. Cognitive flexibility is required in any complex activity where the person needs to consider several kinds of information at the same time. It involves the assessment of the situation and the proposal of strategies and alternatives regarding different situations and everyday demands [18]. Inhibitory control refers to the ability to hold impulsive answers, to avoid distractions, or even to interrupt an action to achieve a goal. This ability is of importance because it increases the effectivity of mental operations and minimizes the demand for information processing $[19,20]$. Central coherence involves the ability to gather and process dispersed information in order to understand the whole in a coherent and integrated fashion [21].

Working memory refers to a system of temporary storage that enables the manipulation of information and improves the learning and thinking abilities, facilitating the integration of environmental sensorial elements and information from the long-term memory [22]. Working memory is represented by two brain systems; one is involved in selective attention towards behaviorally relevant information, and the other is implemented by mainly left hemispheric premotor and parietal brain regions which underlie language functions and may also be involved in the recovery and maintenance of verbal representations during preparation for switching tasks [23].

The abilities of goal identification, planning, executing goal-directed plans, and effective performance are components of EFs [24]. EF deficits have been found in children with ASD, and these impairments are suggested to be associated with their language difficulties, such as the

Stimulation of Executive Functions in Children with ASD inability to utilize inner speech to regulate nonroutine behaviors [7]. Other researchers have found that EF impairments are associated with language deficits intrinsic to ASD $[6,7]$. In contrast, findings from some studies suggest that there is no link between language ability and EFs [4]. Results that connect EFs with language showed an association between both verbal and nonverbal abilities and direct measures of EFs [25]. The contradictory findings in the research may well be due to the large variability among individuals with ASD despite the common diagnosis.

Family dynamics are another important aspect of the intervention process with children with autism, especially when considering the more direct involvement of parents in the intervention process. Several studies have identified a high level of parents' stress, especially regarding the choice between intervention alternatives and the demands involved in providing appropriate treatment and education to their child [26-29]. Parents' beliefs, limits, and challenges are important factors to consider in the intervention process, as parents frequently provide the child's major socialization experiences [30, 31].

Previous studies have considered the inclusion of parents and caretakers in language therapy processes with children with autism. Fernandes et al. [32] studied a group of 36 children between 3 and 12 years and verified the results of a 20 -week period of language therapy with different proposals: individual therapy, dyad with another child, and dyad with the mother. Comparing the results of the functional communicative profile (FCP) and the social-cognitive performance (SCP), these researchers observed that the therapies with participation of the mothers produced the best results. Reagon and Higbee [33] studied daily language intervention with 3 children, aged 2, 3, and 6 years, conducted by their mothers during 2 weeks and reported better results when including the caretakers and the familiar environment in the intervention process. Fernandes et al. [34] also reported positive results after a short period of group mentoring sessions with 26 mothers and their children with ASD aged between 5 and 11 years where the focus was placed on their experience with the children and not on the child's symptoms.

The data from the international survey (see this issue [35]), involving responses from 1,114 speech-language pathologists (SLPs) from 35 countries, suggested that collaborative intervention practices involving parents of children with ASD should be carefully studied, especially because parents frequently report the desire of a more direct involvement in the process [35]. The aim of this study 
was to further explore parents' involvement in the intervention process and to verify if small changes in intervention protocols can improve intervention effectiveness. Specifically, we aimed to observe if the inclusion of tasks involving EFs in the language intervention process with children with autism may be beneficial as observed by improved performance in areas of functional communication and SCP [36].

\section{Methods}

The study was conducted at the Communication Sciences and Disorders Program of the School of Medicine, Universidade de São Paulo, Brazil. The research was approved by the institution's ethics committee, and a parent or caretaker of each participant signed the approved consent form. The research used a quasi-experimental design, where each participant was his/her own control, by comparing different "moments" (pre- and postintervention assessments) of the intervention process within the same participants.

\section{Participants}

A convenience sample was used. There were 24 students with ASD enrolled in an outpatient language service, but 4 children did not complete the intervention, so the data presented are for 20 children who completed the planned intervention. The children had received a diagnosis of ASD by a neurologist or psychiatrist and were aged between 5 and 12 years. They received language therapy for at least 6 months before the onset of this study and were able to engage in cooperative play activities. Their parents were able and willing to participate in the intervention and maintained regular contact with the SLP by phone or digital means.

Since each participant was his/her own control, the inclusion criteria were defined so as to be as broad as possible. A score above $70 \%$ in the SCP assessment was required to obtain some homogeneity among the participants. In addition, the child's behavior in play activities during the semester prior to the study was observed. Verbal and nonverbal children were included. The same criteria were used with both groups. The study did not change the routine of therapeutic intervention procedures at the service where it was conducted.

\section{Procedures}

All participants were assessed regarding the FCP and the SCP [36] in the pre- and postintervention periods implemented. In the FCP, 15-min samples of child and SLP interactive play sessions were video recorded and transcribed to specific protocols. The SLP's transcription and marking were checked by another examiner, and any differences in the transcription were resolved through discussion and repeated listening to the video recordings.

The data used in this study referred to:

- the number of communicative acts expressed per minute,

- occupation of the communicative space (identified by the proportion of communication initiated by each participant of the interaction),

- percentage of interactivity (determined by the proportion of communicative acts with interactive functions), and

- the use of different communicative means (verbal, vocal, or gestural) [37].
Table 1. Examples of the activities proposed in each area

\begin{tabular}{|c|c|c|}
\hline Goals & Activities & \\
\hline $\begin{array}{l}\text { Working } \\
\text { memory }\end{array}$ & $\begin{array}{l}\text { Memorizing sequences } \\
\text { of colored tokens as long } \\
\text { as possible }\end{array}$ & $\begin{array}{l}\text { Step 1: memorizing } \\
\text { pictures from a board } \\
\text { Step } 2 \text { : identifying on a } \\
\text { second board the } \\
\text { pictures that were not in } \\
\text { the first board }\end{array}$ \\
\hline $\begin{array}{l}\text { Cognitive } \\
\text { flexibility }\end{array}$ & $\begin{array}{l}\text { Copying mosaic patterns } \\
\text { with geometric pieces }\end{array}$ & Jigsaw puzzles \\
\hline $\begin{array}{l}\text { Inhibitory } \\
\text { control }\end{array}$ & $\begin{array}{l}\text { Rapid naming sequences } \\
\text { of colors, substituting } \\
\text { the name of one of the } \\
\text { colors by a monosyllable } \\
\text { without meaning }\end{array}$ & $\begin{array}{l}\text { Singing children's songs } \\
\text { and replacing specific } \\
\text { words (or all words of a } \\
\text { specific semantic field) } \\
\text { by clapping }\end{array}$ \\
\hline $\begin{array}{l}\text { Central } \\
\text { coherence }\end{array}$ & $\begin{array}{l}\text { Puzzles with simple } \\
\text { pictures and shapes }\end{array}$ & $\begin{array}{l}\text { Puzzles without pictures } \\
\text { or frames }\end{array}$ \\
\hline
\end{tabular}

Table 2. Average number of areas with progress per participant in FCP and SCP

\begin{tabular}{lrllll}
\hline & $n$ & FCP & SCP & $\begin{array}{l}\text { Average per } \\
\text { subject in FCP }\end{array}$ & $\begin{array}{l}\text { Average per } \\
\text { subject in SCP }\end{array}$ \\
\hline Group 1 & 6 & 15 & 12 & 2.5 & 2 \\
Group 2 & 14 & 48 & 17 & 3.4 & 2.1 \\
\hline
\end{tabular}

FCP, functional communicative profile; SCP, social-cognitive performance.

The SCP assessment identified the child's best performance in 7 different areas: gestural communicative intent, vocal communicative intent, gestural imitation, vocal imitation, tool use, combinatory play, and symbolic play.

The children attending the outpatient clinic formed 2 groups. In group 1, 6 children received stimulation of executive functions (SEF) exclusively conducted by their parents, at home, over a 10week period. During this period, parents and therapists made systematic contact (by phone, WhatsApp, or Skype) to report the children's progress, solve problems, or discuss necessary small changes in the activities proposed. In group 2, 14 children received SEF during individual weekly language therapy sessions with the SLP for a 12-week period. Parents were asked to engage in follow-up activities demonstrated by the SLP at home.

The SEF program involved the use of game activities to facilitate the child's cognitive flexibility, operational memory, inhibitory control, and central coherence. These therapeutic activities could be managed at home by the parents in low-stress situations. Table 1 presents examples of the activities proposed and their goals.
80

Folia Phoniatr Logop 2017;69:78-83 DOI: $10.1159 / 000479586$
Sun/Varanda/Fernandes 
Table 3. Results of the Shapiro-Wilk and Bartlett tests for each group separately and combined analyzing pretest performance compared to posttest performance

\begin{tabular}{|c|c|c|c|c|c|c|}
\hline & \multicolumn{2}{|l|}{ Group 1} & \multicolumn{2}{|l|}{ Group 2} & \multicolumn{2}{|c|}{ Groups 1 and 2} \\
\hline & $\begin{array}{l}\text { Shapiro- } \\
\text { Wilk test }\end{array}$ & $\begin{array}{l}\text { Bartlett } \\
\text { test }\end{array}$ & $\begin{array}{l}\text { Shapiro- } \\
\text { Wilk test }\end{array}$ & $\begin{array}{l}\text { Bartlett } \\
\text { test }\end{array}$ & $\begin{array}{l}\text { Shapiro- } \\
\text { Wilk test }\end{array}$ & $\begin{array}{l}\text { Bartlett } \\
\text { test }\end{array}$ \\
\hline $\mathrm{AM}$ & 0.34 & 0.59 & 0.07 & 0.26 & 0.26 & 0.02 \\
\hline OCS & 0.22 & 0.93 & 0.81 & 0.24 & 0.51 & 0.58 \\
\hline$\%$ inter & 0.13 & 0.56 & 0.00 & 0.11 & 0.00 & 0.94 \\
\hline Communicative intent & 0.05 & 0.24 & 2.75 & 0.44 & 7.06 & 0.42 \\
\hline Imitation & 0.01 & 0.43 & 3.22 & 0.01 & 6.56 & 0.83 \\
\hline Tool use & 0.00 & 0.11 & 4.96 & 1.12 & 3.04 & 0.22 \\
\hline Combinatory play & 0.01 & 0.63 & 7.83 & 0.13 & 2.66 & 0.45 \\
\hline Symbolic play & 1.00 & 2.20 & 2.20 & 1 & 3.20 & 0.05 \\
\hline Total SCP & 0.57 & 0.24 & 2.65 & 0.41 & 3.05 & 0.33 \\
\hline
\end{tabular}

AM, communicative acts per minute; OCS, occupation of communicative space; \% inter, proportion of interactivity; SCP, social-cognitive performance.

\section{Results}

The statistical analysis focused on the interaction of data between pretest and posttest assessments. Tendency to normal distribution and variance homogeneity were tested, respectively, with the Shapiro-Wilk and Bartlett tests. When the results were below 0.05 , the nonparametric tests of Kruskal-Wallis and Wilcoxon were used. When the results were above 0.05 , the parametric tests ANOVA and Tukey were used. Nevertheless, the aim was not to focus on comparing the effects of the 2 interventions on the children. Rather, the focus was on exploring the effect of an individual intervention in each one of the groups.

The first analysis (Table 2) conducted identified the areas where improvement was observed in each participant from pretest to posttest assessments. Improvement in FCP was identified as an increase in the number of communicative acts expressed per minute, change toward balance in the occupation of the communicative space, proportion of communication interactivity, and increase in the use of verbal communicative means. Regarding the SCP, the improvement was identified by the increased scores in each of the 7 areas observed. In Table 3 , the results of the Shapiro-Wilk and Bartlett tests are displayed. It can be noted that few data present a tendency to normal distribution and variance homogeneity, especially when the performance within each group was considered separately.

Stimulation of Executive Functions in Children with ASD
Regarding the performance of participants in group 1 , the results of ANOVA (confirmed by the Tukey-Test) show different performances before and after the intervention period in the proportion of communication interactivity $(p=0.03)$ and in total SCP $(p=0.01)$. In group 2 , a significant difference was observed only for the variable of occupation of communicative space $(p=0.001)$. These results were also confirmed by the Tukey test. The nonparametric analysis of both groups combined identified significant differences between both groups before and after intervention in the proportion of communication interactivity.

\section{Discussion}

This study explored the potential benefit of SEF intervention for children with ASD who received support through an outpatient speech and language therapy clinic in São Paulo, Brazil. The children received the intervention either at home implemented by their parent/caretaker with consultation support by an SLP or by an SLP directly during regular therapy sessions at the clinic.

It is interesting to compare the results of the present study with the one conducted by Fernandes et al. [34]. The children that received SEF in the current study showed more progress in their FCP following intervention than the progress reported by the groups in the previous study, despite the previous study requiring a longer period of intervention (20 sessions compared to between 
10 and 12 sessions in the current study). These results suggest the need for further consideration as to which factors contributed to the positive outcomes. The attribution of specific tasks for the parents to conduct at home, frequently followed up by the SLP, possibly facilitated the parents' work and improved their self-confidence, allowing them to make adjustments and corrections to facilitate their child's language development.

Exploring intervention alternatives with children with ASD that include parents, caretakers, and/or other familiar adults has been shown to be an effective method to improve the quality of the language and social interaction abilities $[28,33]$. The positive differences identified in the areas of occupation of communicative space and proportion of interactivity suggest that further research to examine the hypothesis of an association between the SEF abilities and language development of children with ASD may be warranted. Areas to further investigate are its benefits in increasing interactive communicative skills and social engagement abilities of children with ASD.

In the present study, all parents reported that they observed that their children's communication skills improved in the areas of communication intentionality and turn taking in conversations and increased in their oral vocabulary. However, previous studies that have tried to identify associations between central coherence and social and linguistic abilities have found weak and inconsistent results [38]. The systematic follow-up by the SLPs in the present study may have helped the parents cope with the several demands involved in their child's communication development [33]. Intervention processes with parents and caretakers can include observational learning, didactic workshops, and both passive and active coaching. It is desirable that more research is done to decide on the best combination of approaches for individual families, personalizing the intervention process.

\section{Conclusion}

In this exploratory study, an association was observed between progress in aspects of language development in children with ASD and their participation in an intervention that aimed to stimulate EF abilities. Even with the large individual differences that are characteristic of children with ASD, the results show that SEF had a positive effect on skills measured by the FCP and SCP. The inclusion of parents as mediators for activities conducted at home is a promising technique for increasing the stimulation provided for these children. However, few parents were able to participate in a long-term home-based intervention, and this needs to be considered when planning intervention. These results suggest that more research on different methods to involve parents in their children's intervention and personalized models of intervention with parents/caregivers should be considered.

One of the most relevant limitations of this study is the small number of participants, particularly in the intervention that required parents to be more actively involved in the home intervention. The inclusion of parents in interventions is challenging due to parents' working schedules, personal literacy abilities, and other family or community responsibilities. This continues to be a challenge for future studies to address.

\section{Disclosure Statement}

None of the authors have a conflict of interest to declare.

\section{References}

1 Baron-Cohen S: Autism and Asperger Syndrome. Oxford, Oxford University Press, 2008.

2 Ozonoff S, Pennington B, Rogers S: Executive function deficits in high-functioning autistic individuals: relations to the theory of mind. J Child Psychol Psychiatry 1991;32:1081-1105.

3 Wellman HM, Liu D: Scaling of theory-ofmind tasks. Child Dev 2004;75:523-541.

4 Varanda CA, Fernandes FDM: Syntactic awareness: correlations on the autism spectrum. Psicol Reflex Crit 2014;27:748-758.
5 Jacob R, Parkinson J: The potential for schoolbased interventions that target executive function to improve academic achievement: a review. Rev Educ Res 2015, DOI: 10.3102/0034654314561338.

6 Kimhi Y, Shoam-Kugelmas D, Agam BenArtzi G, Ben-Moshe I, Bauminger-Zviely N: Theory of mind and executive function in preschoolers with typical development versus intellectually able preschoolers with autism spectrum disorder. J Autism Dev Disord 2014;44:2341-2354.
7 Akbar M, Loomis R, Paul R: The interplay of language on executive functions in children with ASD. Res Autism Spectr Disord 2013;7: 494-501.

8 Hill EL: Executive dysfunction in autism. Trends Cogn Sci 2004;8:26-32.

9 Hill EL: Evaluating the theory of executive dysfunction in autism. Develop Rev 2004;24: 189-233. 
10 Memari AH, Ziaee V, Shayestehfar M, Ghanouni P, Mansournia MA, Moshayedi P: Cognitive flexibility impairments in children with autism spectrum disorders: links to age, gender and child outcomes. Res Dev Disabil 2013; 34:3218-3225.

$\checkmark 11$ Rajendran G, Mitchell P: Cognitive theories of autism. Develop Rev 2007;27:224-260.

12 Geurts HM, Corbett B, Solomon M: The paradox of cognitive flexibility in autism. Trends Cogn Sci 2009;13:74-82.

-13 Blijd-Hoogewys EMA, Bezemer ML, Van Geert PLC: Executive functioning in children with ASD: an analysis of the BRIEF. J Autism Dev Disord 2014;44:3089-3100.

14 Vries M, Geurts H: Influence of autism traits and executive functioning on quality of life in children with an autism spectrum disorder. J Autism Dev Disord 2015;45:2734-2743.

-15 Powell KB, Voeller KKS: Prefrontal executive function syndromes in children. J Child Neurol 2004;19:785-797.

16 Ardila A: On the evolutionary origins of executive functions. Brain Cogn 2008;68:92-99.

17 Stemmer B, Whitaker HA: Handbook of the Neuroscience of Language. USA, Academic Press Elsevier, 2008.

18 Geurts JM, Corbett B, Solomon M: The paradox of cognitive flexibility in autism. Trends Cogn Sci 2009;13:74-82.

19 Barkley R: The executive functions and selfregulation: an evolutionary neuropsychological perspective. Neuropsychol Rev 2001;11: $1-29$.

20 Mosconi MW, Kay M, D’Cruz AM, Seidenfeld A, Guter S, Stanford LD, Sweeney JA: Impaired Inhibitory control is associated with higher-order repetitive behaviors in autism spectrum disorders. Psychol Med 2009;39: 1559-1566.

21 Happé F, Frith U: The weak coherence account: detail-focused cognitive style in autism spectrum disorders. J Autism Dev Disord 2006;36:5-25.
22 Baddeley A: Working memory: looking back and looking forward. Nat Rev Neurosci 2003; 4:829-839.

-23 Gruber O, Goschke T: Executive control emerging from dynamic interactions between brain systems mediating language, working memory and attentional processes. Acta Psychol (Amst) 2004;115:105-121.

24 Jurado MB, Rosselli M: The elusive nature of executive functions: a review of our current understanding. Neuropsychol Rev 2007;17: 213-233.

25 Prelock P, Ducker A: Understanding and assessing the social emotional development of children with ASD; in Prelock PA (ed): Autism Spectrum Disorders: Issues in Assessment and Intervention. Austin, Pro-Ed, 2006, pp 251-301.

26 Pakenham KI, Samios C, Sofronoff K: Adjustment in mothers of children with Asperger syndrome: an application of the double ABCX model of family adjustment. Autism 2005;9: 191-212.

27 Benson P, Karlof KL, Sipersteinn GN: Maternal involvement in the education of young children with autism spectrum disorders. Autism 2008;12:47-63.

28 Anbar N, Dardennes R, Prado-Netto A, Kayec $\mathrm{K}$, Contejean Y: Treatment choices in autism spectrum disorder: the role of parental illness perceptions. Res Dev Disabil 2010;31:817828.

29 Harrington J, Patrick P, Edwards K, Brand D: Parental beliefs about autism. Implications for the treating physician. Autism 2006;10: 452-462.

30 Osborne LA, McHugh L, Saunders J, Reed P: Parenting stress reduces the effectiveness of early teaching interventions for autistic spectrum disorders. J Autism Dev Disord 2008;38: 1092-1103.
31 King G, Baxter D, Rosenbaunm P, Zwaigenbaum L, Bates A: Belief systems of families of children with autism spectrum disorders or Down syndrome. Focus Autism Other Dev Disabil 2009;24:50-64.

32 Fernandes FDM, Cardoso C, Sassi FC, Amato $\mathrm{CH}$, Sousa-Morato PF: Language therapy and autism: results of three different models (Fonoaudiologia e autismo: resultado de três diferentes modelos de terapia de linguagem). Pró-Fono Rev Atual Cient 2008;20:267-272.

33 Reagon KA, Higbee TS: Parent-implemented script fading to promote play-based verbal initiations in children with autism. J Appl Behav Anal 2009;42:649-664.

34 Fernandes FDM, Amato CAH, Balestro JI, Molini-Avejonas DR: Orientation to mothers of children of the autistic spectrum about language and communication (Orientação a mães de crianças do espectro autístico a respeito da comunicação e linguagem). J Soc Bras Fonoaudiol 2011;23:1-7.

35 Gillon G, et al: International survey of speechlanguage pathologists's practices in working with children with autism spectrum disorder. Folia Phoniatr Logop 2017;69:8-19.

36 Fernandes FDM, Amato CH, Molini-Avejonas D: Language assessment in autism; in Mohammadi MR (ed): A Comprehensive Book on Autism Spectrum Disorders. Croatia, InTech, 2011, pp 1-22.

37 Santos THF, Fernandes FDM: Functional communication profile - revised: objective description of children and adolescents of the autism spectrum. Rev Soc Bras Fonoaudiol 2012;17:454-458.

38 Laugeson EA, Frankel F, Mogil C, Dillon AR: Parent-assisted social skills training to improve friendships in teens with autism spectrum disorders. J Autism Dev Disord 2009;39: 596-606. 